\title{
Posterior osteosynthesis of a spontaneous bilateral pedicle fracture of the lumbar spine
}

\author{
Sang-Hyun Han, MD, Seung-Jae Hyun, MD, PhD, Tae-Ahn Jahng, MD, PhD, and \\ Ki-Jeong Kim, MD, PhD
}

\begin{abstract}
Department of Neurosurgery, Spine Center, Seoul National University Bundang Hospital, Seoul National University College of Medicine, Seongnam, Republic of Korea
\end{abstract}

\begin{abstract}
Spontaneous bilateral pedicle fractures of the lumbar spine are rare, and an optimal surgical treatment has not been suggested. The authors report the case of a 50 -year-old woman who presented with low-back pain and right leg radiating pain of 1 year's duration. Radiological studies revealed a spontaneous bilateral pedicle fracture of L-5. All efforts at conservative treatment failed, and the patient underwent surgery for osteosynthesis of the fractured pedicle using bilateral pedicle screws connected with a bent rod. Her low-back and right leg pain were relieved postoperatively. A CT scan performed 3 months postoperatively revealed the disappearance of the pedicle fracture gap and presence of newly formed bony trabeculation. In rare cases of spontaneous bilateral pedicle fracture of the lumbar spine, osteosynthesis of the fractured pedicle using bilateral pedicle screws and a bent rod is a motion-preserving technique that may be an effective option when conservative management has failed.
\end{abstract}

http://thejns.org/doi/abs/10.3171/2015.7.SPINE141207

KEY WORDS spontaneous; bilateral pedicle fracture; motion-preserving technique; lumbar; osteosynthesis

I $\mathrm{T}$ is uncommon for fractures to occur spontaneously in the lumbar pedicle. Some cases of unilateral lumbar pedicle fractures related to contralateral spondylolysis s,6, $^{3,22,23}$ or following surgical fusion have been reported.$^{8,11,12,15,18,19,21}$ However, reports of bilateral pedicle fractures without significant trauma, surgery, or a bony abnormality are limited. ${ }^{14,16,20}$ We report a case of spontaneous bilateral pedicle fracture of L-5 in a middle-aged woman and describe the successful treatment with a motion-preserving surgical reconstruction technique.

\section{Case Report}

A 50-year-old woman presented with a 1-year history of severe low-back pain and radiating pain primarily in the lateral aspect of her right leg. The pain was exacerbated by exercise and flexion and improved when lying down. The numeric pain rating scale (NRS) score was 9 points for the low-back pain and right leg pain, and it was difficult for her to walk $30 \mathrm{~m}$. She had been treated with medication (a nonsteroidal antiinflammatory drug and a muscle relaxant), physiotherapy, and epidural steroid injections, but her pain persisted. During physical examination, focal tenderness was observed on palpation over the lumbar region, and pain developed during flexion movements, but no neurological deficit was evident.

Plain radiographs were not suggestive of pedicle fractures. Computed tomography, however, indicated bilateral pedicle fracture of L-5 with sclerotic borders (Fig. 1). Magnetic resonance imaging (MRI) showed fractures at the base of the L-5 pedicles bilaterally.

Because nonoperative management failed, the patient consented to undergo surgery. Under general anesthesia, she was placed in the prone position on a Wilson frame. Using C-arm fluoroscopic guidance, bilateral paramedian incisions were made, and the pedicle screws (Expedium 7.0 $\times 45 \mathrm{~mm}$, DePuy Synthes, Inc.) were inserted into the L-5 vertebral body using a tubular retractor system (METRxMD, Medtronic Sofamor Danek). A midline incision was made, and the muscle was dissected subperiosteally. The lower part of the L-5 spinous process was resected, and the bilateral screws were connected using a properly bent rod (Figs. 2 and 3). 

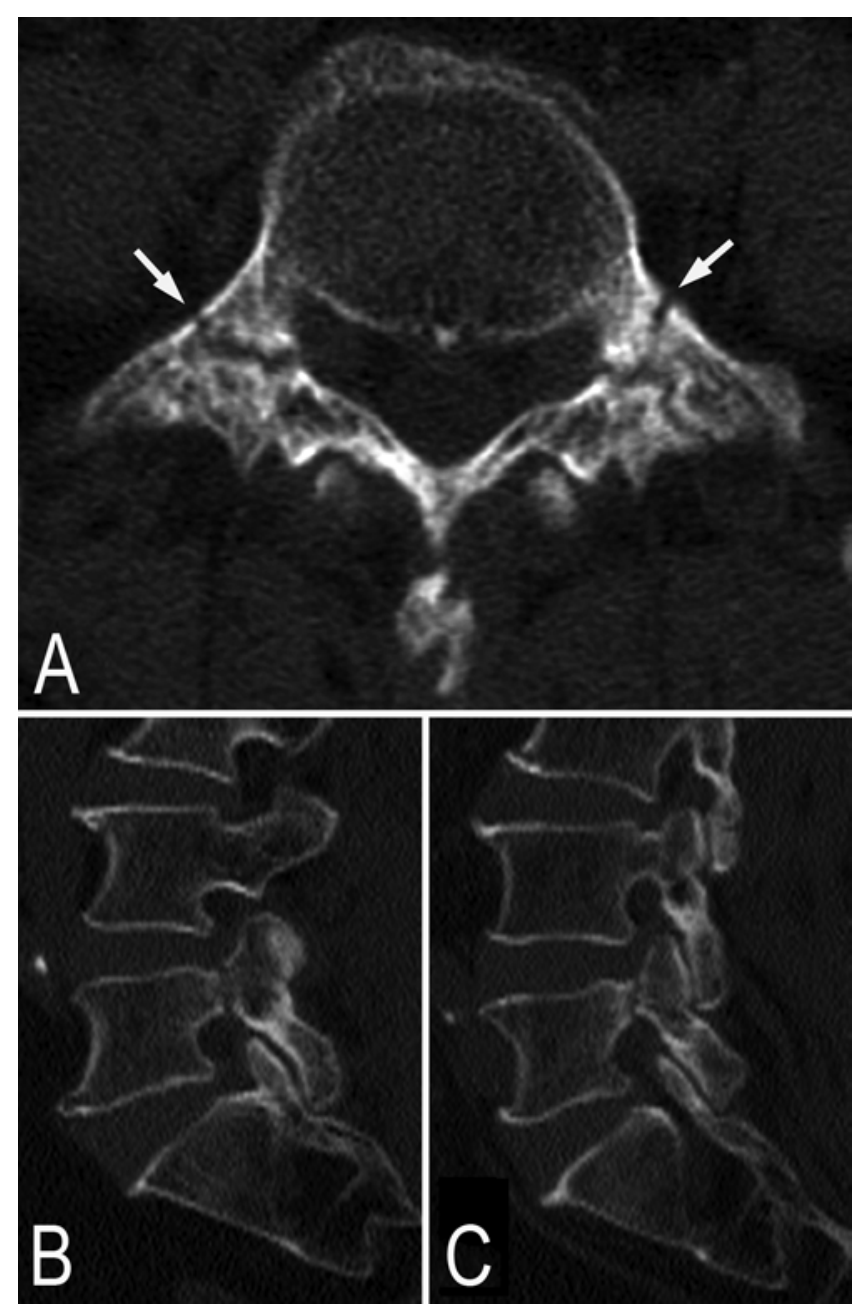

FIG. 1. Preoperative CT images. A: Axial CT scan showing an L-5 pedicle fracture bilaterally (arrows). B and C: Sagittal CT reconstructions showing pedicle fractures at the right $(B)$ and left $(C) L-5$ pedicles.

The patient's lower-extremity pain was greatly reduced postoperatively, and she could walk without any significant low-back pain. By the fourth postoperative week, she returned to her routine daily activities and reported nearly complete resolution of her low-back pain. Follow-up radiographs indicated good instrumentation placement and alignment. Three months postoperatively, her low-back pain and right leg pain were reduced from an NRS score of 9 points to 4 points and she was able to walk more than $1 \mathrm{~km}$. A CT scan revealed that the fracture gaps had disappeared, and reconstitution of bony trabeculation at the fracture sites was evident (Fig. 3). The patient's course over the next 9 months was uneventful, and no worsening was noted. In addition, no malposition or loosening of the pedicle screw and no gap in or displacement of the L-5 pedicles could be found on radiographs of the lumbar spine (Fig. 4).

\section{Discussion}

Cyron and colleagues reported that the weakest point in the neural arch is the pars interarticularis, and the pedicle

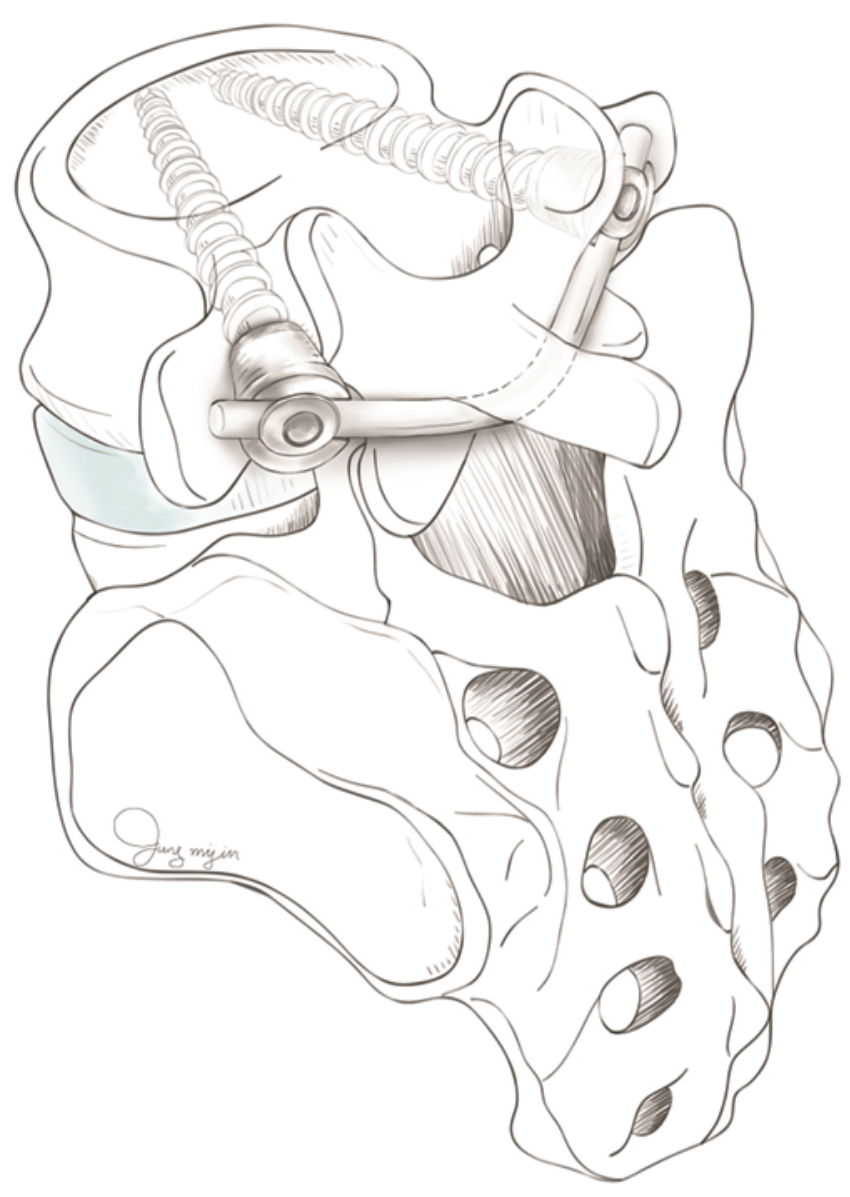

FIG. 2. An illustration of the technique used for posterior osteosynthesis in the present case. Copyright Ki-Jeong Kim. Published with permission. Figure is available in color online only.

is the second weakest point. ${ }^{4,5}$ The moment arm is shorter from the vertebral body to the pedicle compared with that from the vertebral body to the pars, and the pedicle's intrinsic strength is greater than that of the pars interarticularis. ${ }^{4,5,15}$ Therefore, spontaneous lumbar spine pedicle fracture may occur less frequently in the neural arch than spondylolysis.

In unilateral spondylolysis, a contralateral pedicle fracture or sclerotic change can occur.,13,17,22 Pedicle stress fractures after posterior fusion or lumbar interbody fusion have also been reported. ${ }^{8,11,12,15,21}$ Alternatively, cases of spontaneous bilateral pedicle fractures not related to posterior fusion or lumbar interbody fusion have also been reported. ${ }^{1,10,14,16}$

In bilateral pedicle screw fractures not associated with surgery, most studies have reported that management plans started with conservative treatment, such as medication, orthosis, and/or epidural injection, with some patients recovering clinically and radiologically. ${ }^{10,15}$ However, when conservative care failed, surgery was considered. Parvataneni et al. ${ }^{14}$ reported the lumbar interbody fusion technique for treating bilateral lumbar pedicle fractures; however, this technique sacrifices segmental spine motion. Therefore, we adopted osteosynthesis, which mechanically brings the ends of a fractured bone together via wires or 

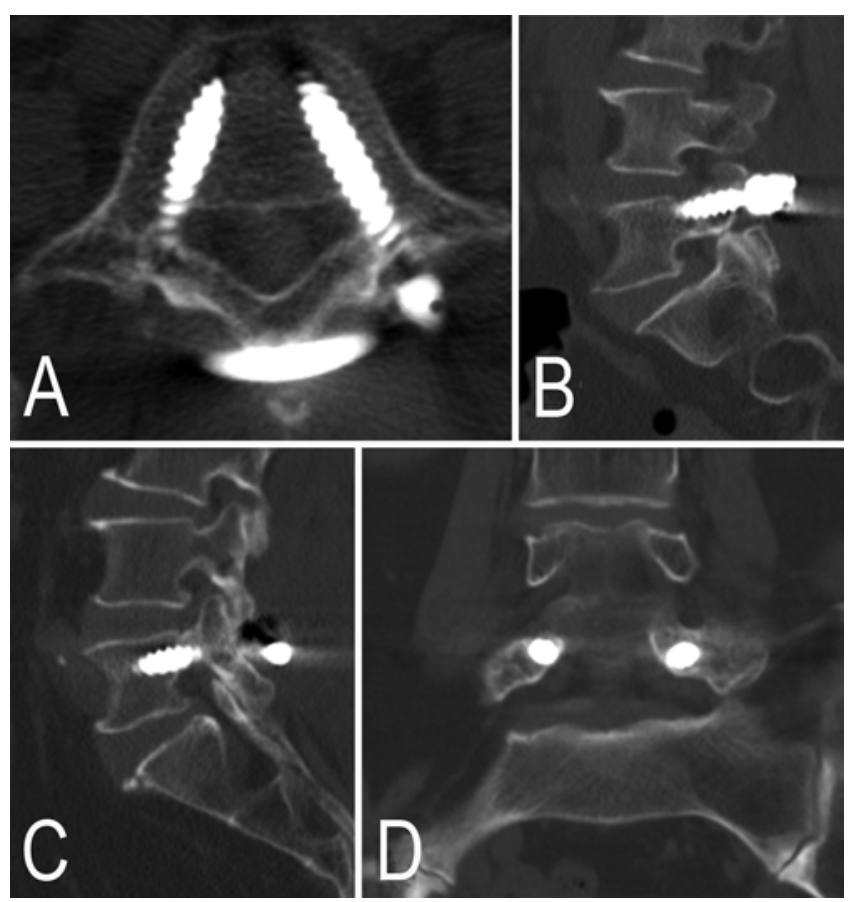

FIG. 3. Follow-up CT images obtained 3 months postoperatively. The axial image (A) shows transpedicular screws bilaterally at the $L-5$ pedicle fracture with healing. The sagittal images ( $B$ and $C)$ show the pedicle screw through the right $(B)$ and left $(C) L-5$ pedicles along with healing fractures. The coronal image (D) shows the pedicle screws are located well in the pedicles bilaterally.

metal plates. Osteosynthesis was proposed by Abeloos et al. ${ }^{2}$ and Jo et al. ${ }^{9}$ for the Jefferson fracture and by Johnson and Wang ${ }^{10}$ for spontaneous bilateral lumbar pedicle fracture. This procedure can maintain the motion segment of the vertebrae. In minimally invasive surgery, the pedicle screws were inserted into the pedicle using a tubular retractor system, and a midline incision was performed to partially remove the L-5 spinous process and to connect the screw heads with the rod. Our method is similar to that

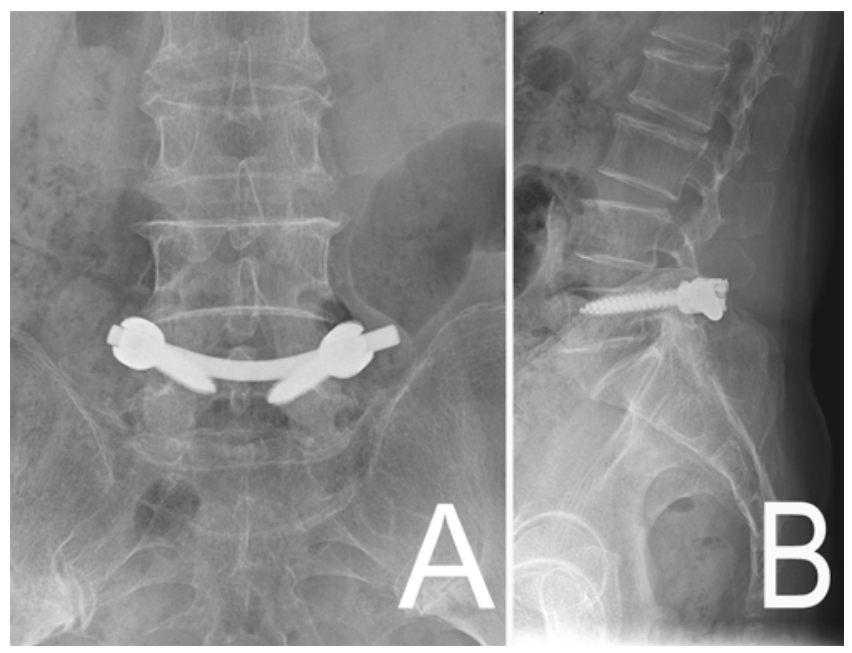

FIG. 4. Anteroposterior (A) and lateral (B) radiographs obtained 1 year after surgery. of Johnson and Wang, ${ }^{10}$ although they used osteosynthesis with only percutaneous screws, which was less invasive. We think that the additional rod fixation at the head of the screw on either side can reinforce the neural arch reconstruction.

Spontaneous bilateral pedicle fractures of a lumbar vertebra are uncommon. When conservative treatment fails, surgery should be considered. We describe a technique for posterior osteosynthesis using pedicle screw fixation and a bent rod, with a successful clinical and radiological outcome. This technique allows rigid fracture stabilization while preserving segmental spine motion compared with previous techniques.

\section{References}

1. Abel MS: Jogger's fracture and other stress fractures of the lumbo-sacral spine. Skeletal Radiol 13:221-227, 1985

2. Abeloos L, De Witte O, Walsdorff M, Delpierre I, Bruneau M: Posterior osteosynthesis of the atlas for nonconsolidated Jefferson fractures: a new surgical technique. Spine (Phila Pa 1976) 36:E1360-E1363, 2011

3. Araki T, Harata S, Nakano K, Satoh T: Reactive sclerosis of the pedicle associated with contralateral spondylolysis. Spine (Phila Pa 1976) 17:1424-1426, 1992

4. Cyron BM, Hutton WC: The fatigue strength of the lumbar neural arch in spondylolysis. J Bone Joint Surg Br 60B:234-238, 1978

5. Cyron BM, Hutton WC, Troup JD: Spondylolytic fractures. J Bone Joint Surg Br 58-B:462-466, 1976

6. Garber JE, Wright AM: Unilateral spondylolysis and contralateral pedicle fracture. Spine (Phila Pa 1976) 11:63-66, 1986

7. Guillodo Y, Botton E, Saraux A, Le Goff P: Contralateral spondylolysis and fracture of the lumbar pedicle in an elite female gymnast: a case report. Spine (Phila Pa 1976) 25:2541-2543, 2000

8. Ha KY, Kim YH: Bilateral pedicle stress fracture after instrumented posterolateral lumbar fusion: a case report. Spine (Phila Pa 1976) 28:E158-E160, 2003

9. Jo KW, Park IS, Hong JT: Motion-preserving reduction and fixation of $\mathrm{C} 1$ Jefferson fracture using a $\mathrm{C} 1$ lateral mass screw construct. J Clin Neurosci 18:695-698, 2011

10. Johnson JN, Wang MY: Stress fracture of the lumbar pedicle bilaterally: surgical repair using a percutaneous minimally invasive technique. J Neurosurg Spine 11:724-728, 2009

11. Knight RQ, Chan DP: Idiopathic scoliosis with unusual stress fracture of the pedicle within solid fusion mass. A case report. Spine (Phila Pa 1976) 17:849-851, 1992

12. Macdessi SJ, Leong AK, Bentivoglio JE: Pedicle fracture after instrumented posterolateral lumbar fusion: a case report. Spine (Phila Pa 1976) 26:580-582, 2001

13. Maurer SG, Wright KE, Bendo JA: Iatrogenic spondylolysis leading to contralateral pedicular stress fracture and unstable spondylolisthesis: a case report. Spine (Phila Pa 1976) 25:895-898, 2000

14. Parvataneni HK, Nicholas SJ, McCance SE: Bilateral pedicle stress fractures in a female athlete: case report and review of the literature. Spine (Phila Pa 1976) 29:E19-E21, 2004

15. Robertson PA, Grobler LJ: Stress fracture of the pedicle. A late complication of posterolateral lumbar fusion. Spine (Phila Pa 1976) 18:930-932, 1993

16. Sadiq MZ: Bilateral pedicle stress fracture in the lumbar spine of a sedentary office worker. Eur Spine J 15 (Suppl 5):653-655, 2006

17. Sairyo K, Katoh S, Sasa T, Yasui N, Goel VK, Vadapalli S, et al: Athletes with unilateral spondylolysis are at risk of stress 
fracture at the contralateral pedicle and pars interarticularis: a clinical and biomechanical study. Am J Sports Med 33:583-590, 2005

18. Sheehan JP, Helm GA, Sheehan JM, Jane JA Sr: Stress fracture of the pedicle after extensive decompression and contralateral posterior fusion for lumbar stenosis. Report of three cases. Neurosurg Focus 13(2):E9, 2002

19. Stanley D, Smith TW: Contralateral pedicle stress fracture. An unusual complication of laminectomy. Spine (Phila Pa 1976) 15:598-599, 1990

20. Traughber PD, Havlina JM Jr: Bilateral pedicle stress fractures: SPECT and CT features. J Comput Assist Tomogr 15:338-340, 1991

21. Tribus CB, Bradford DS: Bilateral pedicular stress fractures after successful posterior spinal fusion for adult idiopathic scoliosis. Spine (Phila Pa 1976) 18:1222-1225, 1993

22. Vialle R, Mary P, de Carvalho A, Ducou le Pointe H, Damsin JP, Filipe G: Acute L5 pedicle fracture and contralateral spondylolysis in a 12-year-old boy: a case report. Eur Spine J 16 (Suppl 3):316-317, 2007

23. Weatherley CR, Mehdian H, Berghe LV: Low back pain with fracture of the pedicle and contralateral spondylolysis. A technique of surgical management. J Bone Joint Surg Br 73:990-993, 1991

\section{Disclosures}

The authors report no conflict of interest concerning the materials or methods used in this study or the findings specified in this paper.

\section{Author Contributions}

Conception and design: Kim. Acquisition of data: Han. Analysis and interpretation of data: Kim, Han. Drafting the article: Kim, Han. Critically revising the article: all authors. Reviewed submitted version of manuscript: all authors. Approved the final version of the manuscript on behalf of all authors: Kim.

\section{Correspondence}

Ki-Jeong Kim, Department of Neurosurgery, Spine Center, Seoul National University Bundang Hospital, Seoul National University College of Medicine, 82, Gumi-ro 173 Beon-gil, Bundang-gu, Seongnam, Gyeonggi-do 463-707, Republic of Korea. email: kijeong@snu.ac.kr. 